\title{
PrátICAS PEDAGÓGICAS DE INTEGRAÇÃo NO PROEJA-IFRN: O QUE PENSAM PROFESSORES E ESTUDANTES*
}

\author{
Ana Lúcia Sarmento Henrique, \\ do Instituto Federal de Educação Ciência e Tecnologia do Rio Grande do Norte. \\ Jose Moises Nunes da Silva, \\ do Instituto Federal de Educação Ciência e Tecnologia do Rio Grande do Norte. \\ Maria das Graças Baracho, \\ do Instituto Federal de Educação Ciência e Tecnologia do Rio Grande do Norte.
}

RESUMO: Este texto é resultado de uma pesquisa desenvolvida pelo NUPED do Instituto Federal de Educação Ciência e Tecnologia do Rio Grande do Norte (IFRN). Como recorte, analisaram-se as práticas pedagógicas que, na perspectiva de professores e estudantes do Ensino Médio Integrado à Educação Profissional na Modalidade de Educação de Jovens e Adultos (Proeja), contribuíram para a integração do currículo. A pesquisa, que ocorreu entre 2009 e 2010, enquadra-se em uma abordagem qualitativa de caráter exploratório e tem como fonte de informação questionários e entrevistas semiestruturadas realizadas com dois grupos de sujeitos dos campi do IFRN que ofertavam cursos Proeja. Constatou-se: a) que os docentes e estudantes referem-se a trabalhos que envolvem mais de uma disciplina, aulas de campo, visitas técnicas, projetos de pesquisa e extensão como possibilidades de integração; b) que tais práticas carecem de sistematização e planejamento coletivo; e c) que ocorrem de forma diferenciada para o ensino médio integrado regular e o Proeja.

Palavras-chave: Proeja. Educação profissional. Currículo integrado.

* Artigo recebido em 02/05/2011 e aprovado em 07/07/2011. 
INTRODUÇÃO

Este trabalho é fruto da pesquisa desenvolvida pelo Núcleo de Pesquisa em Educação (NUPED) do Instituto Federal de Educação Ciência e Tecnologia do Rio Grande do Norte (IFRN), intitulada "Investigando a implementação do ensino médio integrado aos cursos técnicos de nível médio no CEFET-RN a partir de 2005: o currículo e a gestão", com financiamento proveniente do Edital MCT/CNPq, n. 014/2008 - Universal. Como recorte para este trabalho optou-se por analisar as práticas pedagógicas que, na perspectiva de professores e alunos de cursos do Ensino Médio Integrado à Educação Profissional na Modalidade de Educação de Jovens e Adultos (Proeja), oferecidos pelo IFRN, nos campi de Natal Zona Norte, Mossoró, Ipanguaçu e Currais Novos, contribuíram para a integração do currículo.

Com base nesse recorte, escolhemos os seguintes itens de análise: a) o desenvolvimento de atividades que envolvem várias disciplinas no ensino, na pesquisa e na extensão; e b) a realização de aulas de campo, envolvendo disciplinas do ensino médio e da educação profissional.

A análise foi desenvolvida a partir de uma abordagem qualitativa, com caráter exploratório, tendo como principal fonte de informações questionários e entrevistas semiestruturadas realizadas com amostras dos dois grupos de sujeitos em cada um dos campi do IFRN que ofertava cursos técnicos do Proeja. Os questionários foram aplicados entre novembro de 2009 e março de 2010, e as entrevistas realizadas entre os meses de julho e agosto de 2010.

Este artigo está dividido em três itens, além desta introdução. No item 1, apresentam-se as concepções subjacentes à pesquisa e seu percurso metodológico; no item 2 , apresentam-se as práticas pedagógicas de integração que os professores dizem realizar e a percepção que têm os alunos em relação a essas práticas; no item 3, tecem-se algumas considerações acerca da integração curricular no Proeja-IFRN.

\section{Concepções e PERCURSO METOdolóGico}

\subsection{Concepções}

Antes de iniciarmos a discussão, seria interessante refletir sobre a palavra "integrar", que etimologicamente significa completar, tornar inteiro. Ancorados nesse sentido, estaríamos falando em formação omnilateral, "uma concepção de formação humana, com base na integração de todas as dimensões da vida no processo formativo" (RAMOS, 2005, p. 3). Trazendo a 
discussão para o campo da educação profissional (EP), integrar significaria a indissociabilidade entre a educação básica e a educação profissional. Mais que unir os conteúdos da educação básica com os conhecimentos necessários ao desempenho de uma determinada profissão significa pensar uma formação em que os aspectos científicos, tecnológicos, humanísticos e culturais estejam incorporados, integrados e contemplados de forma equânime, em nível de importância e de conteúdo. Assim,

a ideia de formação integrada sugere superar o ser humano dividido historicamente pela divisão social do trabalho entre a ação de executar e a ação de pensar, dirigir ou planejar. Trata-se de superar a redução da preparação para o trabalho ao seu aspecto operacional, simplificado, escoimado dos conhecimentos que estão na sua gênese científico-tecnológica e na sua apropriação histórico-social. (CIAVATTA, 2005, p. 85)

Uma formação nesse sentido precisa materializar-se em um currículo integrado e em práticas pedagógicas que permitam essa integração. Ou, nas palavras de Machado (2010, p. 81),

se a realidade existente é uma totalidade integrada não pode deixar de sê-lo o sistema de conhecimentos produzidos pelo homem a partir dela, para nela atuar e transformá-la. Tal visão de totalidade também se expressa na práxis do ensinar e aprender. Por razões didáticas, se divide e se separa o que está unido. Por razões didáticas, também se pode buscar a recomposição do todo.

Nesse sentido, a discussão sobre currículo integrado vai muito além da disputa de carga horária entre formação geral e específica, pois a centralidade deveria estar em como romper essa dicotomia, na perspectiva de tornar a formação realmente integral sem fragmentações ou falsas oposições entre o que é geral e o que é específico. Particularmente nos cursos do Proeja, a seleção de conteúdos de formação profissional em detrimento daqueles relacionados mais diretamente com a formação científico-cultural dos estudantes revela uma opção pela instrumentalidade da formação contrapondo-se, dessa forma, à concepção do Ensino Médio Integrado (EMI).

Torna-se necessário repensar a concepção de integração vigente, que se restringe a entender o currículo integrado como o deslocamento ou inclusão de disciplinas das áreas técnicas para junto das disciplinas de formação geral. (OLIVEIRA; CEZARINO, 2008, p. 15)

Perseguindo essa postura pedagógica de integração, o Projeto Político-Pedagógico do IFRN contempla uma compreensão global do conhecimento, busca promover maiores parcelas de interdisciplinaridade, 
coloca as disciplinas e cursos numa perspectiva relacional e intensifica a integração dos saberes escolares com os saberes do cotidiano. Essa opção teórica deve materializar-se em práticas pedagógicas organizadas a partir do princípio da interdisciplinaridade. Para este trabalho, entende-se por prática pedagógica as ações que acontecem na escola desde as práticas de organização discursiva até a ação do processo ensino-aprendizagem, como por exemplo, planejamento, reuniões pedagógicas, conselho de classe, eventos científico-culturais, aulas, visitas técnicas etc.

O trabalho interdisciplinar é uma atitude a ser aprendida e apreendida pelos educadores, porque ele

se apresenta como uma necessidade imperativa pela simples razão de que a parte que isolamos ou arrancamos do contexto originário do real para poder ser explicada efetivamente[...], tem que ser explicitada na integralidade das características e qualidades da totalidade. (FRIGOTTO apud RAMOS, 2005, p. 115)

No caso da EP em nível técnico, o desafio em trabalhar o currículo de forma integrada consiste em desconstruir falsas polarizações como trabalho manual versus trabalho intelectual, cultura geral versus cultura técnica, teoria versus prática. Nessa direção, evidentemente, é fundamental que haja interação e planejamento coletivo entre os profissionais que atuam nas disciplinas do Ensino Médio (EM) e da EP em qualquer curso que se propõe a ser integrado.

Ressalta-se, pois, que a organização do tempo e do espaço de atuação dos docentes deve garantir a interação entre os distintos profissionais e assegurar a reflexão conjunta daqueles que atuam no EM e na EP. Isso implica maior esforço organizativo e mais carga horária destinada ao planejamento.

Se a prática pedagógica interdisciplinar é um desafio para o Ensino Médio Integrado (EMI) regular, em se tratando de Proeja, o desafio é ainda maior, pois, conforme expresso no próprio nome, o Programa visa oferecer oportunidades educacionais tanto a jovens e adultos que ainda não finalizaram o ensino fundamental, como àqueles que já o completaram, mas que não concluíram nem o ensino médio nem um curso que os habilite em uma profissão técnica de nível médio.

Nesse sentido, para atender à realidade cultural dos jovens e adultos que se apresentam de forma diferente daqueles que tiveram sua vida acadêmica sem interrupções, o educador necessita repensar sua prática pedagógica com vistas à formação de cidadãos independentes, acreditando 
na sua capacidade de aprender, descobrir, criar soluções e propor novos desafios.

Com base nessas discussões teóricas, esta pesquisa revelou algumas práticas pedagógicas que, na visão dos professores e estudantes do Proeja, propiciam a integração curricular. Entre elas, foram citadas a participação em atividades de pesquisa ou projetos de extensão, as visitas técnicas ou aulas de campo, atividades de laboratório e atividades que envolvem duas ou mais disciplinas.

\subsection{Metodologia e percurso metodológico}

A análise dos dados deste trabalho insere-se no paradigma qualitativo (COHEN e MANION, 1990; GIBBONS, 1995), de caráter exploratório.

A abordagem qualitativa não prescinde de um mergulho sobre dados estatísticos a respeito do fenômeno investigado. Fundamentados nesse pressuposto, elaboramos questionário fechado, cujas respostas receberam tratamento informático para quantificação dos dados. A partir da análise dos questionários, elaboramos entrevistas semiestruturadas. Desse modo, utilizamos como fonte de informação dados extraídos dos questionários, das entrevistas além de documentos institucionais.

Como já explicitado, esses dados fazem parte de uma pesquisa mais ampla, financiada pelo CNPQ e realizada em 2009 e 2010. Para a elaboração deste trabalho, e considerando o objetivo de analisar que práticas pedagógicas contribuíram para a integração das disciplinas na perspectiva de professores e alunos do Proeja, selecionamos duas questões que, com poucas diferenças, estavam presentes nos questionários aplicados a esses sujeitos, conforme Quadro a seguir:

Quadro 1: Questões aplicadas a professores e estudantes

\begin{tabular}{|c|c|}
\hline $\begin{array}{l}\text { No CEFET-RN, para a integração do currículo } \\
\text { estão contribuindo: }\end{array}$ & $\begin{array}{l}\text { No seu curso do CEFET-RN, para a integração } \\
\text { entre as disciplinas do ensino médio e as da } \\
\text { educação profissional contribuíram: }\end{array}$ \\
\hline $\begin{array}{l}\text { a) o desenvolvimento de atividades que } \\
\text { envolvam várias disciplinas no ensino, na } \\
\text { pesquisa e na extensão. }\end{array}$ & $\begin{array}{l}\text { a) a participação em atividades que integrem } \\
\text { professores e conteúdos de duas ou mais } \\
\text { disciplinas. }\end{array}$ \\
\hline $\begin{array}{l}\text { b) a realização de aulas de campo, } \\
\text { envolvendo disciplinas do ensino médio e da } \\
\text { educação profissional. }\end{array}$ & $\begin{array}{l}\text { b) a realização de aulas de campo, } \\
\text { envolvendo disciplinas do ensino médio e da } \\
\text { educação profissional. }\end{array}$ \\
\hline
\end{tabular}

Cabe ainda explicitar que antes dessas questões foi apresentada uma escala de referência variando entre 0 (menor grau de concordância) e 4 
(maior grau de concordância). Além disso, havia a possibilidade de o sujeito marcar uma última coluna caso considerasse não ter elementos suficientes para responder à questão apresentada.

Participaram da pesquisa respondendo ao questionário um total de 60 professores e 63 estudantes. No caso das entrevistas, participaram oito docentes e 49 discentes. No que concerne aos questionários, sua aplicação foi realizada durante reuniões previamente agendadas em cada um dos campi. As entrevistas dos docentes foram individuais, no entanto, no caso dos estudantes, optou-se pela realização de entrevistas coletivas por turma, o que viabilizou a participação de maior número de estudantes e a apreensão do pensamento coletivo de cada turma pesquisada.

\section{PrátICAS PEDAGÓGICAS}

\subsection{Participação em atividades que envolvem várias disciplinas}

As respostas de professores e alunos aos questionários mostram que ambos os grupos acreditam realizar e participar de práticas de integração. Diante da pergunta sobre a participação efetiva em práticas de integração, os alunos e professores deviam responder atribuindo graus de 0 a 4 a essa integração. Entre os docentes, somando-se os graus 3 e 4 de concordância, $58,8 \%$ acreditam que o desenvolvimento de atividades que envolvam várias disciplinas no ensino, na pesquisa e na extensão contribuíram para a integração do currículo. Entre os discentes, esse percentual é de 53,3\%.

Os relatos, embora convirjam em que ainda não há sistematização de práticas pedagógicas voltadas à integração entre as disciplinas do EM e a $E P$, mostram que, em cada campus, algumas práticas sinalizam nessa direção.

$\mathrm{Na}$ entrevista, quando questionado sobre como tentava fazer a integração em seu trabalho, D8 afirmou:

foi um desafio, tive que [...] estudar os objetivos, o perfil de saída do nosso aluno, para poder gerar discussões dentro da disciplina que permitissem ao aluno conhecer melhor o curso que ele tava, contribuir com algum conhecimento para aquele curso [...]. Então como são disciplinas assim um pouco distintas, porque a gente pode dizer: arte e desenho, arte está de um lado e desenho está de outro.

Esse depoimento expressa a preocupação do professor em aproximar suas disciplinas (Artes e Desenho Técnico) da área profissional dos cursos em que atua. No entanto, percebe-se que se trata de uma iniciativa individual. Ele 
afirma ter uma postura interdisciplinar, mas não revela uma prática conjunta com outros docentes.

Sobre a participação em atividades que envolvam mais de uma disciplina, os estudantes de T5, integrado EJA, mencionaram uma única experiência. Segundo E4T5, "três professores de disciplinas diferentes que trabalharam juntos que foi Geografia, Física e Eletricidade. Não me recordo de outro trabalho assim focado para a turma da gente". Para T6 (EMI regular), no entanto, há integração entre as disciplinas técnicas e as de formação geral, conforme expressa E7T6:

A gente estava pagando a matéria de Filosofia e o professor passou um material de lógica pra ajudar a gente a entender melhor o algoritmo que é uma questão de lógica também. Então, assim como teve nas matérias exatas, como em Física, teve também nas ciências humanas essa integração. Teve tanto em Física quanto em Filosofia. Toda a parte da Física que foi de trazer o conteúdo do terceiro ano para o segundo ano pra ajudar porque a gente ia ver a parte de eletrônica e necessitaria do conhecimento [...].

O relato desses estudantes do campus Natal Zona Norte mostra convergências, mas também diferenças significativas. Nos dois exemplos acima, verifica-se o esforço dos professores no sentido de conseguir estabelecer o diálogo entre o conteúdo de diferentes disciplinas integrantes do currículo. Isso é importante, pois demonstra que, apesar das iniciativas não serem generalizadas, abrangem, no caso de T6, professores das três áreas de conhecimento do EM e algumas disciplinas do EP, mesmo que não sejam todos.

Além disso, percebe-se que não há um planejamento orientado ao desenvolvimento dessas ações, no sentido de envolver um maior número de disciplinas e docentes, e que a participação é voluntária e depende do interesse dos professores em realizar esse tipo de atividades.

Por outro lado, para os integrantes de T6, integrado regular, há integração entre as disciplinas técnicas e as de formação geral, enquanto que os estudantes de T5 convergem em que só houve uma experiência de atividade que estabeleceu diálogo entre disciplinas.

Identificam-se, pois, diferenças entre as práticas pedagógicas desenvolvidas nas duas turmas, com prejuízo para os estudantes do Proeja, embora essas turmas sejam da área de Informática e muitos docentes atuem em ambas.

D1, diz que faz a integração da sua disciplina com a Física, a Química e a Matemática, pois acha importante "o docente de formação profissional fazer essa integração dos conhecimentos". E afirma: 
Se nós do profissional, não fizermos isso, vai criar uma dificuldade para que os alunos entendam a nossa disciplina, porque se eles não souberem usar as ferramentas de Física, Química e Matemática, eles não conseguem sair das disciplinas técnicas.

Esse procedimento representa uma oportunidade para a sistematização de um trabalho coletivo junto aos docentes de outras disciplinas de áreas afins, tendo em vista a integração. Não obstante, em sua fala, D1 reforça a dicotomia entre conhecimentos gerais e específicos, algo que se procura romper no currículo integrado. Sua postura aproxima-se à de D8, ao buscar individualmente inter-relacionar conteúdos de disciplinas distintas.

Sabe-se que um dos pontos de partida para que se possa romper com a fragmentação dos conteúdos, na busca de inter-relações no currículo integrado, é a superação do distanciamento entre conhecimentos gerais e específicos. Machado (2010, p. 82) considera que

[...] a construção do currículo integrado exige uma mudança de postura pedagógica; do modo de agir não só dos professores, mas também dos alunos. Significa uma ruptura com um modelo cultural que hierarquiza os conhecimentos e confere menor valor e até conotação negativa àqueles de ordem técnica, associados de forma preconceituosa ao trabalho manual.

Nessa perspectiva, segundo a autora, são fundamentais as práticas compartilhadas e de equipe, tendo o diálogo como elemento fundamental para canalizar a participação, a crítica, a disposição para aprender continuamente em conjunto e a capacidade de trabalhar coletivamente.

D2, que atua no campus Ipanguaçu, afirma que seu trabalho pedagógico está pautado em uma conversa inicial com os alunos, momento em que define, coletivamente, os procedimentos metodológicos e os recursos didáticos a serem adotados durante as aulas. Como exemplo de sua prática, cita o diálogo que estabelece entre a disciplina que ministra e outras do currículo do curso de Agroecologia, mediante a utilização de trechos de livros, pesquisas na Internet e conversas com pessoas mais velhas sobre assuntos da área do curso, destacando os contextos histórico, econômico e social em que ocorrem. Em suas palavras:

Meu trabalho é muito pautado na negociação que tenho com os alunos [...]. A gente fez um trabalho em cima de um filme, foi Os Simpsons - O filme, em que a questão ambiental aparece de maneira muito forte e, a partir disso, os alunos, todos, puderam refletir sobre a importância de ter escolhas maduras, de ter escolhas conscientes acerca do descarte de lixo, de descarte de materiais e assim por diante. 
Essa forma de contextualizar o ensino de uma língua estrangeira, segundo D2, além de desenvolver a consciência sobre o meio ambiente a partir do curso que faz, tem propiciado momentos de reflexão e a formação de atitudes voltadas para o ato de estudar.

D3, também do campus Ipanguaçu, relata que, ao iniciar um determinado conteúdo, procura dialogar com professores de outras disciplinas, no sentido de reforçar conteúdos que se constituem como base para o que vai ser abordado. Em sua entrevista, aponta uma diferença relevante, em termos cognitivos, entre os estudantes do ensino integrado regular e os da EJA:

Os estudantes do [sic] EJA são mais maduros, estão há muito tempo afastados da escola e têm grandes dificuldades para interpretar e para escrever textos. Além disso, muitos são desmotivados, faltam muito e não têm compromisso com a Instituição, dificultando seu engajamento nas aulas teóricas bem como com a pesquisa, embora apresentem interesse e empolgação com as atividades práticas. [...] Eu observo de ponto positivo no [sic] EJA é a atividade prática. Por isso, a nossa sugestão é fazer o negócio mais prático, bem prático mesmo, tipo, pegar a cultura da banana, que é forte na região, e vir do preparo da muda, do plantio, da adubação, do solo, do tipo do solo, das pragas, até o controle.

A sugestão de D3 para trabalhar com os alunos do integrado EJA partindo da atividade prática está correta inicialmente. No entanto, é importante lembrar que não se deve permanecer apenas nas atividades práticas ou abandonar a parte teórica. Isso significa dizer que não se deve separar o trabalho manual do trabalho intelectual, e que a formação do sujeito é a formação do cidadão em que a dimensão intelectual está integrada à dimensão prática.

Essa visão apresentada por D3 em relação aos sujeitos do Proeja é semelhante à que foi identificada nos outros campi pesquisados. Grande parte dos docentes acredita que esses estudantes têm reduzida capacidade para desenvolver o raciocínio abstrato. Diante desse quadro, defendem que a eles sejam destinadas atividades de cunho mais prático. Essa é uma postura determinista e se contrapõe a uma característica fundamental do ser humano que é seu caráter histórico-social e, portanto, de ser inacabado (FREIRE, 1996).

Essa "racionalidade" levou ao fechamento do curso de EMI em Informática no campus Zona Norte Natal, que foi substituído por Manutenção de Computadores, sob a alegação de que esse seria mais adequado a esse público por sua natureza mais prática.

Além disso, transfere toda a responsabilidade pelas dificuldades de aprendizagem para o estudante, como se o docente não fosse responsável pela 
melhoria do processo ensino-aprendizagem, que implica troca, diálogo entre todos os sujeitos envolvidos. Dessa forma, evidencia seu desconhecimento acerca das especificidades dos sujeitos adultos em processo de escolarização. D3 traz uma contribuição que fundamenta essa afirmação, ao relatar que

[...] a diferença de base mesmo é muito forte, é diferença muito grande do pessoal pro regular. Então, às vezes, eu tenho uma certa dificuldade. Eu acho que outros professores devem sentir a mesma coisa e até eu digo na sala: o pessoal diz que EJA é diferenciado, vou trabalhar a mesma coisa só é diferente aqui a carga horária que o regular é ano todo e o EJA é semestral, mas o programa é o mesmo, as atividades são as mesmas, vou trabalhar do mesmo jeito. Mas, infelizmente, às vezes, eu não consigo.

Essa contribuição de D3 explicita a falta de conhecimento institucional e de seus profissionais para trabalhar com o público do Proeja. Evidencia o esforço e a vontade do professor para conseguir trabalhar adequadamente com os jovens e adultos, mas ao mesmo tempo revela sua sensação de incapacidade para fazê-lo e a frustração por não alcançar os objetivos pretendidos.

Na ênfase dada ao fato de que vai trabalhar da mesma forma com os dois públicos está implícito que espera os mesmos resultados. Isso demonstra um raciocínio lógico-matemático aplicado ao campo da educação. Desse modo, o pressuposto em que se baseia D3 é o de que os jovens e adultos deveriam aprender da mesma forma, por meio das mesmas estratégias metodológicas que os estudantes do EMI regular. Entretanto, os sujeitos adultos não aprendem da mesma forma que os adolescentes, porque estão em fases diferentes da vida, têm histórias e experiências de vida distintas, têm necessidades diferenciadas, de maneira que é necessário planejar situações de ensino-aprendizagem distintas e coerentes com a vida e com os processos cognitivos dos sujeitos adultos.

A afirmação de D3 de que o "programa é o mesmo" evidencia uma questão mais ampla, ou seja, os programas das disciplinas foram desenvolvidos quando da elaboração dos planos dos cursos por um grupo de trabalho e, nessa construção, não foram consideradas as especificidades dos sujeitos do Proeja. Assim, o documento que o professor recebe da Instituição para orientá-lo em sua ação docente não leva em conta as particularidades desse público, pois não há referência específica à EJA no que se refere a metodologias, material didático ou avaliação, dentre outras peculiaridades.

Os estudantes de T2, por sua vez, também mencionam exemplos de diálogos entre os conteúdos das disciplinas que compõem o curso de Agroecologia e afirmam que os professores estimulam a relação entre as disciplinas. Eles relatam que, ao longo do curso, tiveram várias aulas compartilhadas por 
professores de diferentes disciplinas como Biologia e Matemática; Filosofia e Matemática; História e Filosofia; Geografia e Cartografia; além de Português que, para eles, dialoga com todas as disciplinas por meio dos textos.

A esse respeito assim se expressa E1T2:"eles sempre mostram: gente essa matéria está ligada a esta outra matéria [...] tem muito [...] eles fazem muito isso aí. Eles estimulam para a gente perceber isso. Sempre as matérias estão ligadas umas às outras". Como exemplo, E2T2 cita "a Agroecologia com Biologia, que estudam o meio ambiente, as plantas e os animais", e acrescenta, "a Biologia com a Matemática. Na aula eles deram exemplos de como a Matemática está bastante presente em Biologia".

Já E3T2 diz: “a gente também pode ver que a Filosofia está ligada à Matemática. Nós também tivemos aulas de Filosofia falando sobre a relação da Filosofia com a Matemática". E E5T2 afirma: "Português, eu acho que está ligado a todas as matérias. Porque sempre todas as matérias precisam de textos que a gente tem que ler. Há também, além da leitura, a escrita".

Mencionaram também atividades que estabeleceram relações entre teoria e prática e entre disciplinas do ensino médio com as disciplinas próprias da formação profissional. A esse respeito, E6T2 diz: “O professor de Química nos levou para conhecer o sistema biogestor, que é retirado das fezes e tal [...] que daqui a alguns dias vai fornecer energia para a Instituição".

Para D10, do Campus Currais Novos, há uma preocupação dos professores em buscar a integração. Como exemplo, cita a integração de suas disciplinas Tecnologia do Leite e Embalagem, Rotulagem e Logística com as disciplinas Língua Portuguesa e Artes, respectivamente. Além dessas, diz que a disciplina Controle Estatístico da Qualidade pode ser trabalhada em parceria com várias disciplinas e que "Bioquímica dos Alimentos, como o próprio nome já diz, é bastante interessante estar trabalhando em parceria com a Química. Então, assim, não falta interdisciplinaridade dentro das disciplinas".

Também afirma D10 que a"escola tem propiciado, tem mostrado que há esse caminho. Tem falado desses projetos de interdisciplinaridade, projeto integrador; e, eu acho assim, a principio foi a escola que abriu os olhos e, num segundo momento, parte dos professores".

E4T8, por sua vez, lembra o estudo sobre alimentos da Antiguidade desenvolvido na disciplina História que, de certa forma, reflete no curso de Alimentos, até porque

no passado não tinha essa coisa de preservação e conservação de alimentos e hoje a gente já tem. Mas lá no passado eles entenderam que tinha que ter uma conservação, mas hoje já é diferente. Eu acho que tem muito a ver 
quando no caso a História traz o passado da Alimentação do povo antigo para agora, e a gente vê as diferenças.

E2T8 complementa dizendo que

o professor de História faz muita associação mesmo de alimentos que eram consumidos antigamente e a conservação nas civilizações antigas, o que eles comiam, qual era a comida típica deles e a associação de hoje. A professora de Embalagens também, com os primeiros tipos de embalagens e as embalagens de agora. Outros professores também trabalharam isso aí.

Enfim, E5T8 lembra que o professor de Língua Inglesa sempre chamava a atenção dos alunos para a importância de se compreender um pouco da língua estrangeira, sobretudo na área de Alimentos. Complementando, E11T8 afirmou que "o professor de Inglês trabalhou a questão de frutas, alimentos. Nos ensinou a pronunciar os alimentos em Inglês. E ele fez essa associação".

Como se pode perceber, a prática pedagógica dos docentes no Campus Currais Novos, a exemplo dos demais campi em análise, reflete a forma linear de organização do conteúdo escolar, e o diálogo entre as disciplinas se dá pela vontade de alguns professores.

\subsection{Participação em projetos de pesquisa ou de extensão}

A investigação constatou a incipiente participação de estudantes da modalidade EJA em práticas que envolvem projetos de pesquisa e extensão. Esse fato, no entendimento de D3, se justifica pelas lacunas cognitivas materializadas pelas dificuldades em leitura e escrita. Por outro lado, E4T2 relata que realizou um trabalho envolvendo as disciplinas biologia e agroecologia que resultou na construção de um herbário, constituído de plantas de várias espécies da região, formando uma "biblioteca de plantas." E3T2 lembra do projeto de biogestor que está sendo desenvolvido na Instituição para fornecer energia para o Campus.

A análise dos relatos constatou a existência de práticas distintas entre os estudantes do Proeja e os do integrado regular, no que se refere à oportunidade de participação em projetos de pesquisa, com prejuízo dos primeiros, pois os estudantes de T5 não fizeram nenhuma alusão à participação em projetos dessa natureza.

\subsection{Realização de visitas técnicas e aulas de campo}

Questionado sobre as práticas pedagógicas que contribuem para a integração curricular, D8 e os estudantes de T4 mencionaram as aulas 
de campo e as visitas técnicas como práticas que contribuem para essa integração, pois, em geral, as atividades envolvem mais de uma disciplina.

D7 relata que precisa moldar seu trabalho docente à realidade de cada curso em que trabalha. Por isso, procura demonstrar que a"Matemática é a ferramenta necessária para que ele possa dar continuidade à questão da parte prática profissional". Acrescenta também, que a interação de sua disciplina com outras se dá por intermédio das aulas de campo, em que precisa "usar a matemática como ferramenta estatística", e nos próprios encontros de Informática, onde "desenvolve a exposição de uma série de modelos matemáticos que são importantes para o desenvolvimento do curso".

D4, da área de Códigos, Linguagens e suas Tecnologias, afirma que desenvolveu alguns trabalhos ainda incipientes junto aos professores da área profissional que resultaram na produção de relatórios de viagens de campo e de visitas técnicas. Acredita D4 que essa prática é um caminho para que os professores possam começar a desenvolver um trabalho integrado.

Já E8T8 entende não ser fácil conciliar a parte de Alimentos com outras disciplinas, mas percebe que as aulas de campo referem-se à parte profissional e que tem outras "viagens normais voltadas para as disciplinas normais/básicas só que nem sempre são voltadas a Alimentos".

As visitas técnicas e aulas de campo são ações institucionalizadas no IFRN. No entanto, elas vêm ocorrendo com a definição de um local, e o professor, voluntária e isoladamente, elabora sua estratégia para explorar o conteúdo da sua disciplina.

Essas práticas ensejam a interdisciplinaridade, pois sempre envolvem conhecimentos de mais de uma área, mas não garantem que ela ocorra. A interdisciplinaridade exige um diálogo entre as disciplinas em torno do objeto de estudo comum. Desse modo, exige um planejamento coletivo dos docentes que vão participar dessas atividades no sentido de buscar as conexões existentes entre as disciplinas envolvidas.

\section{CONSIDERAÇÕES FINAIS}

De uma maneira geral, percebe-se a existência de práticas pedagógicas de integração, embora não sistematizadas. Uma prática mencionada de forma recorrente foi a articulação entre professores para promover o diálogo entre conteúdos de distintas disciplinas no desenvolvimento do currículo. As práticas relatadas foram basicamente de dois tipos, uma delas diz respeito ao ajuste na sequência dos conteúdos de uma disciplina, a fim de preparar os estudantes para o conteúdo de outra disciplina. Nessa perspectiva, houve 
muitos relatos do tipo:"eu pergunto: professor, você trabalhou esse assunto? [...] dá pra você falar um pouco, que eu vou entrar na próxima aula" (D3).

Há outra prática relacionada com a busca do diálogo entre as disciplinas que é mais elaborada e exige maior grau de articulação entre os professores. Consiste em considerar um objeto comum de estudo e explorá-lo a partir de duas ou mais disciplinas. Nessa perspectiva, também ocorreram vários depoimentos nos distintos campi, como, por exemplo, o trabalho conjunto entre as disciplinas de Biologia e Agroecologia na construção de um herbário no laboratório, citado por E7T2.

Embora haja relatos desse tipo de prática em todos os campi investigados, eles são mais recorrentes em Ipanguaçu, onde os estudantes relataram que ao longo do curso tiveram várias aulas compartilhadas por professores de diferentes disciplinas.

Ainda merecem destaque as ações de alguns professores que procuram estabelecer relações entre a disciplina em que atuam e as demais, independentemente de diálogo com outros colegas, conforme evidenciam os relatos de D1 e D8 e os dos alunos de T2.

No conjunto de práticas relatadas até agora, constata-se o potencial que elas têm de contribuir para a realização do trabalho coletivo e o estabelecimento de diferentes níveis de diálogo entre as disciplinas, o que sinaliza na direção da interdisciplinaridade, expressando aspectos relevantes na construção do EMI.

Apesar disso, também se concluiu que essas práticas são realizadas de forma assistemática, pois falta uma ação intencionada e coordenada na direção de provocá-las. Dessa forma, são desenvolvidas individualmente ou por pequenos grupos, o que dificulta sua institucionalização.

Além disso, cabe destacar que tais práticas se restringem à busca da interdisciplinaridade, que é um dos princípios do EMI, mas não o único. Assim, não incidem em princípios importantes que são centrais na concepção de formação humana integral, como são o trabalho como princípio educativo, o todo como síntese das múltiplas relações, e homens e mulheres como seres histórico-sociais. Diante desse quadro, tais práticas não contribuem para avanços nas dimensões epistemológica e ético-política do currículo integrado.

Quanto à participação em eventos técnico-científicos, cabe ressaltar que o mais referenciado pelos entrevistados foi a Expotec, uma exposição tecnológica realizada anualmente pelo IFRN em cada um de seus campi, na qual são apresentados experimentos, protótipos, atividades artísticoculturais, palestras e mesas redondas sobre assuntos relacionados com a temática escolhida para o evento, sessões de apresentações de pôsteres e 
comunicações, além de minicursos sobre temas diversos dentro das áreas de atuação de cada campus.

Considera-se, pois, essa prática como espaço potencialmente importante, no sentido de contribuir para a materialização do EMI. Os dados da pesquisa permitem concluir que esse potencial é parcialmente convertido em ações concretas que contribuem à integração curricular ao promover certo diálogo entre as distintas disciplinas e áreas do conhecimento. Não obstante, mesmo para esse evento, a participação é voluntária tanto de docentes como de estudantes. Em geral, não há um cronograma a ser seguido, de modo que as atividades são extremamente pontuais e desenvolvidas nos dias que antecedem o evento.

Com relação às aulas de campo, as conclusões foram as mesmas, de maneira que não cabe repeti-las.

Outra prática pedagógica institucional é o incentivo à participação dos estudantes em grupos de pesquisa. Esse é outro tipo de prática importante na perspectiva da integração e da formação humana integral. Ela instiga a curiosidade do estudante em relação ao mundo que o cerca, gera inquietude, e, em consequência, dificulta que aceitem "pacotes fechados" de visão de mundo, de informações e de saberes, quer sejam do senso comum, escolares ou científicos. No entanto, a participação dos estudantes do Proeja em práticas dessa natureza não ocorrem na mesma medida em que ocorre a participação dos adolescentes. Para D3, isso ocorre porque "os alunos do integrado regular são mais motivados, querem ficar na escola e participar. Muitos até trabalham comigo com pesquisa voluntariamente, sem qualquer ajuda financeira".

Essa afirmativa revela que D3 desconsidera as especificidades dos jovens e adultos estudantes, que, muitas vezes, precisam trabalhar para garantir sua subsistência e/ou a de seus familiares.

As práticas relatadas pelos sujeitos revelam pouca compreensão do que seja o currículo integrado ou de como se pode sistematizar o trabalho interdisciplinar. Nesse sentido, considera-se relevante a reorganização do tempo e do espaço de atuação docente nos campi pesquisados, a fim de incorporar à sua prática pedagógica, dentro da respectiva jornada de trabalho, carga horária destinada às redes de pesquisa (RP) de grupos, espaço de planejamento e lócus de formação continuada dos docentes. Nessa perspectiva, além das discussões do cotidiano escolar é necessário incorporar às RPs, leituras e outras formas de estudo que contribuam para uma maior apropriação dos princípios que fundamentam o projeto político-pedagógico 
(PPP) em geral e, em particular, do currículo integrado, e dos princípios da inter/multi/pluri e transdisciplinaridade, da modalidade EJA e da EP.

Evidentemente, o acesso a esse conhecimento não garante o efetivo engajamento de todos, de forma idealizada, nas ações do EMI no Proeja. Entretanto, possibilita conhecer a realidade, o que contribuirá para uma tomada de consciência, necessária a uma mudança de atitude.

Não sem razão Santomé (1998) lembra que o currículo pensado de forma integrada permite, de fato, abordar conteúdos que são objeto de atenção em várias áreas de conhecimento; favorecer a visibilidade dos valores, ideologias e interesses presentes em todas as questões sociais e culturais; articular dinamicamente trabalho-ensino-comunidade, com uma imediata contribuição para esta última; e propiciar uma efetiva integração entre ensino e prática profissional.

Por isso, é imprescindível que a prática pedagógica docente voltada para a integração tenha a compreensão de que uma visão interdisciplinar deve estar presente na organização dos conteúdos de todos os cursos, de sorte a permitir aos estudantes não só se apropriarem dos conhecimentos técnicos inerentes ao curso, como também compreender a sociedade em que vivem e contribuir para que possam dela participar de forma autônoma, crítica e solidária.

\section{PEDAGOGICAL INTEGRATION PRACTICES IN PROEJA:THE THINKING OF TEACHERS AND STUDENTS}

ABSTRACT:This study grew out of a survey conducted by NUPED at the Instituto Federal de Educação Ciência e Tecnologia do Rio Grande do Norte (IFRN). It analyzes the pedagogical practices which contributed to curriculum integration, according to the teachers and students involved in integrated Secondary and Vocational Education in the Education of Young People and Adults Modality (Proeja). The survey, undertaken between 2009 and 2010, is a qualitative approach of an exploratory nature based on information obtained from questionnaires and semi-structured interviews conducted with two groups of subjects on the IFRN campuses offering Proeja courses. It was found that: a) teachers and students refer to assignments involving more than one subject, field courses, technical visits, research and outreach projects as possibilities for integration; b) such practices lack systematization and collective planning; c) and there is a difference between the way they are carried out for the regular integrated Secondary School and for Proeja.

KEYWORDS: Proeja. Vocational education. Integrated curriculum. 


\section{REFERÊNCIAS}

CIAVATTA, M. A formação integrada: a escola e o trabalho como lugares de memória e de identidade. In: FRIGOTTO, G.; CIAVATTA, M.; RAMOS, M. (Orgs.). Ensino Médio Integrado: concepção e contradições. São Paulo: Cortez, 2005. p. 83-105.

COHEN, L.; MANION, L. Método de investigación educativa. Madrid: Muralla, 1990.

FREIRE, P. Pedagogia da autonomia: saberes necessários à prática educativa. 25. ed. São Paulo: Paz e Terra, 1996. (Coleção Leitura)

GIBBONS, M. et al. The new productions of knowledge.The dynamics of science and research in contemporary societies. London: Sage, 1995.

MACHADO, L. R. de S. Ensino médio e técnico com currículos integrados: propostas de ação didática para uma relação não fantasiosa. In: MOLL, Jaqueline et al. (Orgs.). Educação profissional e tecnológica no Brasil contemporâneo: desafios, tensões e possibilidades. Porto Alegre, RS: Artmed Editora, 2010. p. 80-95.

OLIVEIRA, E. C. de; CEZARINO, K. R. de A. Os sentidos do Proeja: possibilidades e impasses na produção de um novo campo de conhecimento na formação de professores. Anais... 31ª Reunião Anual da ANPED. Caxambu: ANPED, 2008.

RAMOS, M. Possibilidades e desafios na organização do currículo integrado. In FRIGOTTO, G.; CIAVATTA, M.; RAMOS, M. (Orgs.). Ensino Médio Integrado: concepção e contradições. São Paulo: Cortez, 2005. p. 106-127.

Concepção de ensino médio integrado. [s.l.: s.n.], 2008, p. 1-30. Disponível em: <http://www. iiep.org.br/curriculo_integrado.pdf >. Acesso em: 20 jan. 2009.

RELATÓRIO da pesquisa "Investigando a implementação do ensino médio integrado aos cursos técnicos de nível médio no CEFET-RN a partir de 2005: o currículo e a gestão". Natal, 2011.

SANTOMÉ, J. Globalização e interdisciplinaridade: o currículo integrado. Porto Alegre: Artes Médicas, 1998. 
Ana Lúcia Sarmento HenriQue: Licenciada em Letras, com Especialização em Linguística Textual e em PROEJA pelo IFRN, com Mestrado em Letras - Linguística Aplicada pela UFRN e Doutorado em Educação pela Universidade Complutense de Madri. Trabalha com educação a distância no Campus EAD e participa do Grupo de Pesquisa em Educação (NUPED), ambos do IFRN.

Email: ana.henrique@ifrn.edu.br

Maria das Graças Baracho: Pedagoga, com mestrado em Educação pela UFRN e professora desde 1979 do Instituto Federal de Educação, Ciência e Tecnologia do RN (IFRN), Campus Natal Central. Atualmente aposentada, é coordenadora do Curso de Pós-Graduação Lato Sensu em Educação Profissional Integrada à Educação Básica na Modalidade Educação de Jovens e Adultos, e participa do Grupo de Pesquisa em Educação (NUPED) no IFRN.

E-mail: sraca.baracho@ifrn.edu.br

Jose Moises Nunes da Silva: Licenciado em Matemática pela Universidade Federal do Amazonas (1985), Bacharel em Ciências Contábeis pela Universidade Federal do Amazonas (1992), com pós-graduação em Auditoria pela Pontifícia Universidade Católica de Minas Gerais (1995) e mestrado em Desenvolvimento Regional pela Universidade Federal do Amazonas (2004). É professor do IFRN e doutorando do Programa de Pós-graduação em Educação pela UFRN.

E-mail:moises.silva@ifrn.edu.br 